\title{
Conselhos Comunitários de Segurança: a violência em diálogo
}

\section{Inês Nogueira ${ }^{1}$}

Resumo: Os conselhos comunitários de segurança pública do Rio de Janeiro representam uma mudança institucional na área das políticas públicas de segurança. Trata-se de um canal de abertura que permite a participação no plano local, caracterizado pela busca da instauração de diferentes padrões de interação entre governo e sociedade em torno do tema segurança. A consolidação do papel desses conselhos depende não só da presença de organizações e representantes sociais aptos a reivindicar múltiplos interesses, como o comprometimento do governo em reconhecer essas arenas como canais privilegiados na relação entre poder público e sociedade. $O$ exercício dos conselhos comunitários de segurança pública pode colaborar para o aprofundamento da democracia brasileira na medida em que aposta numa sociedade civil mais organizada e atuante e num Poder Executivo e órgãos governamentais mais dispostos ao diálogo.

Palavras-chave: conselhos comunitários de segurança pública; políticas de segurança pública

Abstract: The Rio de Janeiro's public safety community councils represent an institutional change in the area of public safety policies. It is an open channel that allows participation in local search, characterised by the introduction of different patterns of interaction between Government and society around the safety matter. The consolidation of the role of such councils depends not only on the presence of social organizations and representatives able to claim multiple interests, but also the Government's commitment to recognize these arenas as privileged channels in the relationship between Government and society. The exercise of public security community councils can contribute to the Brazilian democracy in the way that encourages to build a more organized an active civil society and an Executive power and government institutions more willing to dialogue.

Keywords: public safety community councils; public security policies

Résumé: Les Conseils Communautaires de Sécurité Publique de Rio de Janeiro représentent un changement institutionnel dans le secteur des politiques publiques de sécurité. Il s'agit d'un canal d'ouverture qui permet la participation dans le plan local, caractérisé par la recherche de l'instauration de différentes normes d'interaction entre le gouvernement et dela société autour du sujet sécurité. La consolidation du rôle de ces Conseils dépend de la présence d'organisations et de représentants sociaux aptes à revendiquer de multiples intérêts, aussi que de l'engagement du gouvernement à reconnaître ces arènes comme des canaux privilégiés dans la relation entre pouvoir public et société. L'exercice des Conseils Communautaires de Sécurité Publique peut collaborer pour l'approfondissement de la démocratie brésilienne dans la mesure où qu'on fait confiance à la société civile plus organisée, opérante et au Pouvoir Exécutif et aux agences gouvernementales plus disposés au dialogue.

Mots-Clés: Conseils Communautaires de Sécurité Publique; politiques de securité publique.

\footnotetext{
${ }^{1}$ Inês Nogueira é mestranda do Programa de Pós-Graduação em Ciências Sociais da Universidade do Estado do Rio de Janeiro (PPCIS/UERJ).
}

INTRATEXTOS, Rio de Janeiro, Número Especial 01, pp.18-31, 2010 


\section{Introdução}

A implementação de espaços institucionalizados de participação, sem dúvida, é o resultado de uma lenta mudança tanto das instituições como da sociedade nos últimos trinta anos. Estas mudanças possibilitaram que houvesse tanto aberturas nas instâncias decisórias como ampliação e modificação das suas agendas políticas. A partir da ampliação de instâncias representativas públicas de ordem local, foram abertas oportunidades para que os cidadãos discutissem e negociassem as regras que envolvem o processo decisório, o que possibilita o fortalecimento democrático.

Ao longo dos anos 90, a ampliação do conceito de participação foi uma das dimensões mais evidenciadas no processo de democratização. A forte adesão a este ideário veio acompanhada de mudanças nos significados atribuídos à governabilidade democrática e à instauração do Estado de Direito no contexto do declínio do regime autoritário.

Nos anos 70 havia uma ênfase na necessidade de controlar os potenciais desestabilizadores da democracia, buscando manter o grau de interferência da sociedade sob controle. Já no que se refere ao campo político e econômico, a preocupação com a democracia era substituída pela manutenção da ordem política, num contexto de forte intervenção do Estado na economia e na regulação da vida social.

Esses princípios conservadores continuaram presentes na pauta da reforma do Estado ao longo da década de 80, pois não houve um projeto amplo que modificasse as características da atuação estatal (BARRETO, 2000, p. 3). A demanda por mudanças se deu através de uma sequência de planos pouco eficientes que prometiam uma saída rápida para problemas como a inflação e a recuperação do crescimento econômico. Nesse caso, o Plano Cruzado, em 1986, pode ser considerado um divisor de águas em relação à crença de que a manutenção do desenvolvimento seria possível. A discussão sobre a necessidade de uma reforma do Estado, na sua pluralidade de competências (gestão da economia e políticas públicas) entrou em pauta na política do país. O desenvolvimento econômico passou a ser pensado através da parceria entre Estado e sociedade civil, dando-se ênfase aos aspectos sociais, culturais e ambientais, que durante muito tempo foram suprimidos em nome da estabilização da economia. Em síntese, as mudanças propostas trouxeram consequências para o modelo democrático que passou a se configurar no Brasil ao longo das décadas de 80 e 90.

INTRATEXTOS, Rio de Janeiro, Número Especial 01, pp.18-31, 2010 
Na década de 90, a concepção de governabilidade do Estado passou a depender da capacidade de administrar e diversificar espaços de negociação e a inclusão de novos atores no processo participativo. A ampliação da participação civil, neste contexto, apareceu como saída ao problema de equacionar políticas públicas eficientes com baixo teor de investimentos.

Deste modo, consolidou-se a noção de que a participação da sociedade civil seria indispensável para a execução de políticas públicas mais eficientes. Sem dúvida, a discussão acerca da descentralização do poder público contribuiu para esta idéia: atender as expectativas macroeconômicas do Estado na medida em que aumentava a participação dos atores da sociedade civil.

\section{1 - Instalação de novos espaços de participação}

Considera-se que o aumento da participação da sociedade nos aparelhos do Estado reflete uma perspectiva de ajuste econômico. Porém, o aumento da participação também reflete as demandas apresentadas nas mobilizações de algumas camadas da sociedade que reivindicam espaços de reconhecimento e de influência nas decisões políticas (Oliveira, 2008).

Neste contexto, o processo de reforma do Estado direcionado para as idéias de democratização do país se concretizou através da Constituição de 1988, que estabeleceu as diretrizes para implantação do sistema democrático. Ao instalar modelos de democracia semidireta, como a articulação entre elementos representativos (eleições livres e competição entre partidos) e elementos diretos (referendum, plebiscito e lei popular), esta Constituição possibilitou uma maior articulação e garantias para participação social no desenho de algumas políticas públicas ${ }^{2}$.

O conjunto de reformas no Estado e a formulação de aparatos legais oriundos deste período possibilitaram o advento de algumas mudanças institucionais que passaram a buscar, por um lado, as garantias do processo de redemocratização e, por outro lado, a efetivação de políticas para a inclusão de segmentos da população excluídas do poder político.

Alguns elementos contribuíram para diversificação das formas de ação coletiva. Segundo Avritzer, neste momento, se destacaram a renovação na atuação do movimento

INTRATEXTOS, Rio de Janeiro, Número Especial 01, pp.18-31, 2010 
sindical, a introdução de movimentos sociais de ajuda mútua, e, na medida em que a classe média passava a atuar, um conjunto de movimentos culturais e associações comunitárias. Todos se constituíram como espaços públicos de ordem mais plural. Além disso, o autor aponta para o surgimento de associações temáticas relativas às questões de gênero, meio ambiente e direitos humanos (Avritzer, 1995, p. 162).

A respeito da constituição de 1988, o ativismo de algumas camadas da sociedade foi atendido de certa forma. A "Constituição Cidadã" representou um alargamento estatal sob as condições do Estado de Direito. Sua elaboração concedeu ampla margem para a abertura de grupos sociais organizados e trabalhos de ordem descentralizada. Este processo de descentralização representou uma verdadeira inovação no campo da administração pública. Em um momento em que a organização política do país era colocada em xeque, a nova Carta transferiu para as esferas regionais a competência de prover tanto os serviços sociais, como a infra-estrutura. Além disso, a descentralização - mais do que pluralizar as responsabilidades que antes eram atribuições centralizadas nos ministérios - trouxe outras conseqüências para a organização da federação.

Pela primeira vez, uma carta constitucional brasileira dava autonomia aos Municípios da Federação. Até então, somente o Distrito Federal tinha autonomia administrativa. O que o texto da constituição estabeleceu ao atribuir novos formatos nas esferas que integravam a federação foi que, a partir daquele momento, haveria, para instâncias municipais, uma transferência da prestação de serviços que antes não eram de sua atribuição. Contudo, cabe compreender que a descentralização nesta conjuntura, tanto atendia as demandas da sociedade em ampliar sua participação no aparelho do Estado, como respondia a necessidade de racionalizar e compartilhar os gastos com outras esferas de governo.

No que tange ao processo de reformas e ao próprio processo de redemocratização, surgiram na sociedade civil espaços de conscientização, prestação de serviços e de reivindicações de aumento da participação na elaboração de políticas públicas. Diversos são os autores que avaliam os resultados deste novo arranjo federativo como positivo, pois implicou na ampliação do processo decisório (Arretche, 2002).

No período posterior à Constituição mencionada, além da crescente participação da sociedade no processo decisório de políticas públicas proporcionada pela descentralização,

\footnotetext{
${ }^{2}$ Constituição Federal de 1988, artigo $1^{\text {o }}$, parágrafo único.
}

INTRATEXTOS, Rio de Janeiro, Número Especial 01, pp.18-31, 2010 
houve uma onda de iniciativas no que tange à produção de bens e de serviços coletivos. Uma das inovações na busca de resolução de problemas coletivos foi a construção de parcerias com o setor público não-estatal. A reforma do Estado possibilitou a criação de parcerias sob a forma de "organizações não-governamentais", "terceiro setor", "setor sem fins lucrativos", todas as iniciativas com o intuito de buscar soluções para problemas que seriam de ordem pública ${ }^{3}$.

Nesses novos contornos das políticas e da administração pública observou-se a ampliação da participação nos "Conselhos de Políticas Públicas". Na participação da sociedade em forma de Conselhos, há, segundo a literatura especializada, diferenças tanto no formato institucional, como na influência exercida por seus atores. As formas mais frequentes eram os "Conselhos Populares", espaços autônomos em que a população pressionava o governo no atendimento de suas demandas; os "Conselhos Administrativos", ou "Conselhos Municipais", direcionados à gestão de serviços como escolas, creches e hospitais; e por fim, os "Conselhos Comunitários", criados por iniciativa do poder executivo estatal. Estes conselhos gestores de políticas públicas seriam espaços públicos e de composição plural, em que, mediante o processo deliberativo, os integrantes da sociedade civil poderiam formular e controlar a execução das políticas setoriais.

Com isso, os conselhos criados nos anos 90 foram definidos como parte da estratégia de modernização do Estado e ampliação da sua legitimidade política. Estes foram inseridos num projeto que objetivava a partilha da responsabilidade na gestão dos bens públicos de acordo com as motivações determinadas acima. No que diz respeito à área de segurança pública, estes conselhos possibilitariam a difícil tarefa de construir o diálogo entre os interesses da comunidade e a atuação dos policiais.

\section{2 - Conselhos Comunitários de Segurança: sua proliferação}

A introdução de arranjos participativos, ou mesmo da noção de participação, ganhou força com o processo de mudança institucional que emergiu em direção à redemocratização do país. Contudo, quando se trata de políticas públicas de segurança, vem à tona a disputa de

\footnotetext{
${ }^{3}$ Existem diferenciações funcionais entre os espaços públicos não-governamentais, porém, não é objeto deste trabalho fazer uma análise aprofundada sobre eles. Ver: PEREIRA, L. C. Bresser \& GRAU, Nuria Cunnil (orgs.). O público não estatal na reforma do Estado. Rio de Janeiro: Editora Fundação Getúlio Vargas, p. 51-85.
}

INTRATEXTOS, Rio de Janeiro, Número Especial 01, pp.18-31, 2010 
espaços e atribuições historicamente conflitivas. Apesar de o trabalho policial ter imediata relação com a comunidade - na medida em que suas atribuições são relacionadas às demandas da população por serviços contra a criminalidade e manutenção da ordem pública - observa-se também que essa relação tem caráter permanentemente conflituoso. É importante destacar que a relação entre polícia e comunidade tem tido sempre um caráter ambíguo. Isso porque a polícia tem como atribuição reagir às situações consideradas criminosas, que muitas vezes esbarram na cultura autoritária e desconsideram preceitos fundamentais da cidadania. Entretanto, apesar da relação nem sempre amistosa entre polícia e comunidade, há o desejo de formular experiências que possibilitem um contato mais próximo para resolução de problemas pertinentes à segurança e às possíveis maneiras para a sua solução.

Diante destas considerações, ao longo da década de 90, percebeu-se o interesse das Secretarias Estaduais de Segurança Pública em elaborar discursos que visassem promover a eficiência, racionalidade administrativa e modernidade dos aparatos materiais da polícia. Além de se tratar de um período bastante favorável para a criação de espaços ampliados de participação, como já foi mencionado, políticos de diferentes organizações partidárias perceberam o potencial de mobilização popular gerado pela violência. Desde o final dos anos 80, com o gradativo aumento da violência e criminalidade nas metrópoles e cidades médias brasileiras, esta temática se tornou um dos principais alvos eleitorais de diversos programas de governo. Com isto, os governos buscaram, cada vez mais, desenvolver agências de controle da criminalidade, preocupados com a autorização e legitimação da sociedade e, principalmente, com a opinião pública.

No que se refere às iniciativas adotadas no Rio de Janeiro a este respeito, percebeu-se que, ao longo dos anos 80, o cenário da violência em diversos pontos da cidade já tinha alcançado proporções alarmantes. Atrelado a estes fatores, nos anos 90, algumas iniciativas de "lei e ordem" ainda serviram de incentivo a política truculenta das instituições policiais. A política de "gratificação faroeste", uma controvertida premiação aos policiais durante o governo Marcelo Alencar, incentivou a polícia a desempenhar a sua atuação de forma ainda mais violenta. Esta premiação recompensava os policiais com gratificações aos atos de "bravura", o que, sem dúvida, estimulou o enfrentamento e o aumento do número de vítimas fatais principalmente nas áreas mais pobres da cidade.

No momento em que a questão dos direitos humanos se fortalecia, era preciso pensar em políticas de caráter mais democrático, ou seja, propostas que conseguissem dar conta, 
simultaneamente, da necessidade de reforço policial-judicial e das demandas da sociedade civil.

No Rio de Janeiro, a política de conselhos na área da segurança se fez presente a partir da gestão de Anthony Garotinho. Durante o pleito de 1998, o até então prefeito de Campos, com o apoio do ex-governador Leonel Brizola, apareceu com uma proposta de governo que priorizava as políticas sociais e a ampliação da cidadania. Em linhas gerais, a área da segurança pública foi a âncora dos seus discursos de candidatura (Soares, 2000, p. 51).

Garotinho ganhou as eleições sensibilizando os eleitores de que seria possível adotar posturas eficientes na área da segurança pública, sem que fosse necessário apelar para ataques ofensivos e truculentos. Toda a sua candidatura foi baseada na proposta de estabelecer um governo que privilegiasse os princípios da cidadania e dos direitos humanos. Já nos seus primeiros meses de governo, desencadeou uma série de projetos voltados para a modernização gerencial da área de segurança. Lançou programas como Delegacia Legal, que tinha a perspectiva de criar métodos mais modernos de planejamento e gerenciamento da polícia. Além disso, fortaleceu programas como o Disque Denúncia e os centros de referência contra a homofobia e a discriminação racial. Estas iniciativas partiram do pressuposto que com a ampliação da democracia, seria estimulada uma postura mais cidadã da população. $\mathrm{O}$ alargamento do conceito de prevenção, segundo as propostas de governo de Garotinho, colocava o problema da violência e da criminalidade como um fenômeno sócio-político, isto é, de interesse de todos os segmentos da sociedade e não somente uma tarefa das polícias.

Ainda no ano de 1999, por meio da uma resolução da Secretaria de Estado de Segurança, o governo fez valer uma determinação prevista desde a promulgação da Constituição Estadual de 1989, que estabelecia a criação dos Conselhos Comunitários ${ }^{4}$. Deste modo, além de criar os Conselhos Comunitários de Segurança Pública, condicionou o repasse de verbas aos municípios destinados à segurança e à criação destes conselhos ${ }^{5}$.

Desta forma, a criação dos Conselhos Comunitários de Segurança, como veículo conduzido pelo Estado visou abrir espaços de diálogo entre Estado e Sociedade. Esta criação tinha o objetivo de, por um lado, melhorar a imagem da polícia junto à população, possibilitando a formação de um campo mais aberto em que estratégias e prioridades tivessem

\footnotetext{
${ }^{4}$ Constituição Estadual do Estado do Rio de Janeiro, 1989, artigo 182, inciso $2^{\circ}$.

${ }^{5}$ Instituto de Segurança Pública. Série Conselhos Comunitários de Segurança. Polícia e Comunidade: temas $e$ desafios na implantação de conselhos comunitários de segurança. 2007, p. 9-14.
}

INTRATEXTOS, Rio de Janeiro, Número Especial 01, pp.18-31, 2010 
o auxílio da comunidade, e, por outro lado, introduzir um caráter preventivo à ação policial, com o controle de possíveis focos de tensões que pudessem se transformar em incidências criminais.

Além disso, ainda durante a administração de Anthony Garotinho, foi criado o Instituto de Segurança Pública (ISP). Esta autarquia foi instalada com o objetivo de subsidiar a Secretaria de Estado de Segurança na implementação de políticas públicas, por meio de pesquisas, projetos e análises informativas e assegurar a participação da sociedade na construção dessas políticas. Para os municípios interessados em aperfeiçoar seus serviços relacionados à Segurança Pública, o Instituto realizou convênios com estas localidades podendo prestar consultorias técnicas adaptadas às necessidades locais.

O Instituto foi criado com a função de se consolidar como órgão de referência na produção de conhecimento em segurança pública e promoção da participação social. A partir de 2004, o ISP passou a ser o órgão responsável pela promoção dos conselhos comunitários, levando as questões de segurança para a esfera local. Em todo o Rio de Janeiro, foram criados Conselhos Comunitários de Segurança. Estes conselhos foram instituídos não em municípios ou regiões do Estado, mas em Áreas Integradas de Segurança Pública (AISP), que são áreas circunscritas dos Batalhões da Polícia Militar e delegacias. As AISPs também foram criadas como forma de demarcação territorial do Estado para fins de planejamento e monitoramento das políticas de segurança pública. Com esta divisão em áreas, seria possível facilitar o monitoramento e o planejamento das atividades, qualificação dos dados estatísticos, distribuição geográfica da população e do crime, indicadores sócio-econômicos e, finalmente, a construção de "mapas de risco" mais acurados para a distribuição dos serviços de forma mais equânime. No total, 40 AISPs foram criadas no Estado, cada qual representada pelos comandantes dos batalhões da Polícia Militar e delegados titulares das delegacias distritais. Desta forma, dentre as principais funções esperadas com a criação das AISPs, caberia possibilitar o compartilhamento, controle e avaliações permanentes, com o objetivo de aperfeiçoar estratégias de atuação específicas para cada área.

Segundo a resolução de criação dos conselhos, eles deveriam ser realizados mensalmente, nas AISPs, em cafés comunitários, em que policiais, moradores e lideranças locais pudessem se reunir e promover avaliações relativas aos problemas de segurança de forma amena e informal. Deveriam entrar em pautas nestas reuniões, avaliações sobre as incidências criminais, elucidação de delitos e a qualidade dos serviços prestados pela polícia.

INTRATEXTOS, Rio de Janeiro, Número Especial 01, pp.18-31, 2010 
Neste sentido, a comunidade seria convidada a ajudar a identificar os crimes mais comuns, discutir soluções e acompanhar os resultados das medidas adotadas.

Portanto, os Conselhos Comunitários de Segurança do Rio de Janeiro foram criados como parte de uma série de mudanças voltadas para a modernização da gestão policial. De acordo com Luiz Eduardo Soares, intelectual que esteve inserido nas políticas de intervenções em segurança pública do governo Garotinho, as polícias no Rio de Janeiro não tinham aparatos voltados para o planejamento, investigação, análise de dados e avaliação dos seus trabalhos. Segundo ele, “as polícias são máquinas pesadas e lentas, nada inteligentes e criativas, (...) cada vez mais só prendem em flagrante, porque pouco se investiga; limita-se a reagir depois que os crimes já ocorreram.” (Soares, 2006).

A criação dos Conselhos Comunitários de Segurança nasceu em um contexto que se pretendia estabelecer parcerias entre os profissionais de polícia e a comunidade. Apesar de também possuir sustentação legal, como a maioria dos conselhos gestores nas diversas áreas das políticas públicas, como os de educação e saúde por exemplo, os Conselhos Comunitários de Segurança Pública apresentam uma diferença importante: eles não se configuram como uma instância deliberativa. Os conselhos gestores funcionam como instâncias deliberativas com amparo legal para a elaboração de políticas de fiscalização, fortalecendo uma gestão de caráter mais democrático. Estes conselhos possuem autorização para influir na formulação de políticas públicas, estabelecendo prioridades na formulação de orçamentos e uso dos recursos públicos, apontando para proposta de compartilhamento de poder. Os conselhos gestores têm como principal competência deliberar, enquanto arenas criadas com o objetivo de favorecer a reforma democrática.

Os conselhos de segurança, contudo, não possuem as mesmas propostas apresentadas pelos conselhos de outras áreas. $\mathrm{O}$ fato de não se configurarem enquanto espaço deliberativo não implicaria necessariamente na inviabilidade de cumprir o papel de aumentar a participação da sociedade civil. Os conselhos de segurança buscam tratar tanto assuntos comuns em todo Estado, como também identificar as questões de ordem local que exigem tratamento e respostas diferenciadas. No ínterim, são freqüentemente levantadas em boa parte dos conselhos respostas às ações do poder público junto à população de rua e a necessidade de aumento de efetivo nas ruas. Sem dúvida, este também se torna um espaço em que a polícia pode expressar junto à comunidade as suas dificuldades institucionais como escassez de homens e seus limites de recursos materiais (Teixeira, 2006, p. 198-219).

INTRATEXTOS, Rio de Janeiro, Número Especial 01, pp.18-31, 2010 
Sem dúvida, diante do cenário de violência em que se encontram as grandes capitais do Brasil, em especial o Rio de Janeiro, os Conselhos de Segurança surgem como um novo canal de comunicação entre a comunidade e a polícia em busca de um interesse comum: a redução da violência. Como vimos, a proposta dos conselhos é colocar a segurança pública como responsabilidade coletiva, abrindo a oportunidade para a sociedade pensar e participar da construção da sua própria segurança.

Entretanto, apesar da determinação do governo de manter a frequência dos conselhos comunitários, ao longo do tempo, muitos conselhos foram descontinuados. Em diversos casos, além da falta de apoio por parte da população, não havia um núcleo comum de procedimentos em relação ao funcionamento dos conselhos. Somente em 2003, através de uma nova Resolução ${ }^{6}$, foi possível revitalizar os conselhos. Contudo, somente outra resolução, em $2005^{7}$, na tentativa de resolver a questão de organização e controle de informações vindas dos conselhos, solicitou que o Instituto de Segurança Pública passasse a avaliar o funcionamento destes encontros.

O diagnóstico do ISP verificou a necessidade de discutir novos rumos para a estruturação e funcionamento dos $\operatorname{conselhos}^{8}$. Como, em sua fundação, não haviam sido estabelecidos procedimentos mínimos de funcionamento, não era possível acompanhar as ações realizadas e ficava, portanto, difícil o estabelecimento de regras claras. Com isto, a partir deste período, o ISP resolveu estabelecer regras mínimas de funcionamento, além da preocupação com a adaptação das peculiaridades locais.

Muito embora estejam vinculados ao poder público, os conselhos possuem o caráter independente. De acordo com Carla Eicheler, é possível apontar quatro funções dos conselhos de segurança:

1) Cooperar com as autoridades de maneira geral e, no caso das autoridades municipais ou em atuação nos bairro, apoiá-las nos pleitos de recursos e providências que sejam feitos às autoridades da esfera estadual e/ou federal;

2) Constituir-se em um mecanismo de controle externo das atividades dos órgãos do sistema;

\footnotetext{
${ }^{6}$ Resolução SSP n ${ }^{\circ} 629$, de 19 de maio de 2003.

${ }^{7}$ Resolução SSP n ${ }^{\circ} 781$, de 08 de agosto de 2005.

${ }^{8}$ Diagnóstico realizado no I Fórum dos Conselhos Comunitários de Segurança, realizado na UERJ, em 2004, foram discutidas questões como a distinção entre café e conselho e a elaboração de um guia prático para participantes de Conselhos de Segurança. Apud.: Teixeira: 2006.
}

INTRATEXTOS, Rio de Janeiro, Número Especial 01, pp.18-31, 2010 
3) Reivindicar a atuação do poder público, em situações específicas, de interesse da coletividade abrangida pelo conselho;

4) No caso dos conselhos de bairros, e eventualmente nos pequenos municípios, organizar a autoproteção comunitária e o gerenciamento dos riscos, articuladamente com a polícia. (Silva, 2005)

Além do nível local, os conselhos de segurança também possuem graus de atuação estadual e municipal. Na esfera estadual, participam dos conselhos, as autoridades de segurança pública, do sistema prisional, do Ministério Público e Poder Judiciários estaduais e representantes de entidades e associações civis. No nível municipal, participam os representantes do Executivo municipal, autoridades policiais, responsáveis pela Justiça Criminal e Ministério Público no município e representantes da sociedade civil. Já em instância local, objeto de estudo deste trabalho, reúnem-se os responsáveis mais diretos das instituições policiais (delegados da polícia civil e comandantes do batalhão militar) e a comunidade, muitas vezes representadas por instituições religiosas, comerciais, entidades filantrópicas, escolas e associação de moradores. Portanto, é no espaço local que governo e sociedade, pela primeira vez, obtêm a possibilidade de definir as medidas de segurança específicas para a sua AISP.

Os assuntos discutidos nas reuniões dos conselhos comunitários são elaborados em uma agenda que deve conter a identificação dos problemas, acompanhamento crítico das medidas adotadas pelos policiais e uma lista de prioridades. No final de cada mês, a coordenação da AISP deve elaborar uma avaliação sobre a situação do controle da violência na área de acordo com seus próprios critérios de soluções e abordagem dos problemas. Deste modo, percebe-se que os conselhos comunitários de segurança não têm o poder de deliberar quanto às estratégias e soluções do problema da violência. Apesar da contribuição atribuída aos conselhos em apontar as ansiedades locais, a segurança não deixa de ser, em momento algum, monopólio do saber especializado das instituições policiais. Embora a tentativa de se buscar um consenso com a comunidade através do aprofundamento do diálogo, as polícias não são obrigadas a obedecer a agenda definida por ela.

Portanto, a competência dos conselhos de segurança é de ser consultivo. Mesmo que nem todos os problemas e sugestões citados nas reuniões sejam colocados em prática, as atas e relatórios são registrados para análise e acompanhamento. Os conselhos são responsáveis por diagnosticar os problemas de segurança pública na localidade com base tanto nos demonstrativos de incidências criminais divulgados mensalmente pelo Instituto de Segurança

INTRATEXTOS, Rio de Janeiro, Número Especial 01, pp.18-31, 2010 
Pública, como nas demandas exigidas pela comunidade. Apesar de não assumirem atribuições deliberativas ou executivas, os conselhos poderiam propiciar a cooperação entre polícia e a sociedade local através dos seus diagnósticos e de atividades que valorizem as instituições policiais frente à comunidade.

Os conselhos estimulam, portanto, a possibilidade de intervir na própria noção do que se entende por políticas públicas. Como no Brasil a noção de público se distingue pelo vínculo que este possui com seus "proprietários", sejam particulares ou o próprio Estado, as coisas públicas se tornam coisas privadas. Segundo Kant de Lima, devido às nossas profundas tradições jurídico-patrimonialistas, seria mais relevante distinguir as coisas pela forma de sua apropriação, isto é, se são apropriáveis pela coletividade ou se são apropriadas particularizadamente, tanto pelo Estado por outros particulares. Isto é de grande relevância porque, à medida que as coisas fossem apropriadas pela coletividade, a maneira de conservála e protegê-las seriam a disciplina e o respeito pelo espaço alheio. Da mesma forma, quando fossem apropriadas de forma particularizada, o modo de garanti-las seria a repressão. Esta é, portanto, a distinção entre políticas públicas coletivas, e políticas particularistas do Estado sobre aquilo que ele entende que lhe pertence e, por conseqüência, àqueles que a ele estão de alguma forma vinculados ou nele instalados (Lima, 1979, p. 105-124).

Este pensamento se aplica ao caso dos conselhos comunitários da segurança pública, no sentido de que eles podem ser alinhados a concepções polarizadas: podem corresponder a uma elaboração de ações destinadas a atender ao interesse público, no sentido de coletividade, ou podem corresponder à adoção de rótulos novos que servem apenas para mascarar antigos conteúdos. Nesse último caso, os conselhos fariam parte de práticas que o Estado compreenderia como lhe pertencendo.

Para além de compreender as políticas públicas de segurança como um problema de política, ou uma questão apenas do governo estadual, o ponto de partida que se coloca através da criação dos conselhos comunitários de segurança é considerar que a segurança pública baseada na idéia de que é dever do Estado de proteger os indivíduos - resultará de uma ação de todos os poderes, de todas as instâncias do governo e da sociedade civil.

Portanto, pode-se evidenciar que ao longo das três últimas décadas tanto o poder público como a sociedade civil organizada buscaram mecanismos de participação mútua. De acordo com os seus devidos interesses, defenderam a perspectiva de que a democracia se tornaria mais eficiente a partir da proximidade entre os órgãos públicos e as demandas locais.

INTRATEXTOS, Rio de Janeiro, Número Especial 01, pp.18-31, 2010 
Com isso, projetos em que a sociedade civil é "chamada" a atuar, participando junto ao Estado, apontam para a tendência descentralizadora que o país vem tomando, sobretudo, a partir da década de 90. Contudo, cabe uma investigação criteriosa quanto ao funcionamento destes encontros, o que eles representam para a comunidade envolvida e o grau de envolvimento dos conselheiros dentro do jogo político com as instituições do Estado.

\section{REFERÊNCIAS BIBLIOGRÁFICAS}

ARRETCHE, Marta. Federalismo e relações intergovernamentais no Brasil: a reforma dos programas sociais. Rio de Janeiro, Revista Dados, v. 45, n 3, 2002.

AVRITZER, Leonardo. Cultura política, atores sociais e democratização. ANPOCS: Revista Brasileira de Ciências Sociais, $\mathrm{n}^{\circ}$ 28, ano 10, junho, 1995.

BARRETO, Helena Motta Salles. Crise e Reforma do Estado Brasileiro. Juiz de Fora: Editora UFJF, 2000.

BRETAS, Marcos. Police and Community in Rio de Janeiro: An Historical Overview. In: Errol MENDES et al (orgs.). Democratic Policing and Accountability. England: Aldershot: Ashgate Publishing Ltd, 1999.

LIMA, Roberto Kant de. Carnavais, malandros e heróis: o dilema brasileiro do espaço público. In: Gomes, Laura Graziela. et al (orgs.). O Brasil não é para principiantes: carnavais, malandros e heróis 20 anos depois. Rio de Janeiro: Fundação Getúlio Vargas, 1979.

OLIVEIRA, Otair Fernandes de. Conselho Municipal de Educação no Brasil: práticas políticas e deliberação pública em Nova Iguaçu. Rio de Janeiro: Tese apresentada no concurso de título de Doutorado. Programa de Pós-Graduação em Ciências Sociais da Universidade do Estado do Rio de Janeiro, 2008.

INTRATEXTOS, Rio de Janeiro, Número Especial 01, pp.18-31, 2010 
SENTO-SÉ, João Trajano (org.). Prevenção da Violência: o papel das cidades. Rio de Janeiro: Civilização Brasileira, 2005.

SILVA, Carla Eichler de Almeida. Particapação Comunitária em Nível Local: a experiência dos conselhos comunitários de segurança pública. Rio de Janeiro: Dissertação apresentada ao Curso de Pós-Graduação em Ciência Política da Universidade Federal Fluminense como requisito parcial para obtenção do Grau de Mestre, 2005.

SOARES, Luiz Eduardo. Meu Casaco de General - quinhentos dias no front da segurança pública do Rio de Janeiro. São Paulo: Companhia das Letras, 2000.

Segurança tem Saída. Rio de Janeiro: Sextante, 2006.

TEIXEIRA, Paulo Augusto. Os Conselhos Comunitários de Segurança Pública do Rio de Janeiro. Revista Comum v. 11 - nº 26 (janeiro/junho 2006). 